\title{
Average evoked response and stimulus intensity in identical and fraternal twins
}

\author{
MONTE S. BUCHSBAUM* \\ Laboratory of Psychology, National Institute of Mental Heal th \\ Bethesda, Maryland 20014
}

\begin{abstract}
A group of 30 monozygotic (MZ) and 30 dizygotic (DZ) adult twins were studied, using visual and auditory average evoked response (AER) techniques. Vertex evoked responses were found to show very great similarity in $\mathrm{MZ}$ twin pairs and little similarity in DZ twin pairs. Greater heritability of positive than of negative components and a heritability of AER parameters of change with stimulus intensity suggest a functional neurophysiological, rather than a simple anatomic source, of the AER twin similarities.
\end{abstract}

One of the most striking characteristics of the average evoked response (AER) in man is the variation from person to person in waveform and amplitude. Thus, the finding of almost identical AERs (see Figs. 1 and 2) in monozygotic twin pairs compellingly illustrates the importance of familial factors in the AER. Previous studies employing AER techniques have found greater waveform and amplitude similarities in monozygotic (MZ) twins than in dizygotic (DZ) twins (Dustman \& Beck, 1965; Osborne, 1970; Lewis et al, 1972; Young et al, 1972). The significance of these findings is uncertain, since similarities in waveform or amplitude may reflect a variety of relatively nonspecific anatomical features. If, however, higher heritabilities were found for the variation of a particular component with some stimulus parameter, we could have increased confidence that genetic influence on a neurophysiological characteristic, rather than purely an anatomic one, was being assessed.

Later components of the AER, especially after $200 \mathrm{msec}$, change more than earlier ones as a function of attention (see Hillyard et al, 1973, for recent references), arousal (Eason et al, 1969), habituation (Roth, 1973), and expectancy (Buchsbaum et al, 1974a; Tueting et al, 1971). We might, therefore, expect greater experiential effects with late components. In contrast, studies on males, females, and patients with chromatin negative gonadal dysgenesis (Buchsbaum et al, 1974b) have suggested that early components at $80-140 \mathrm{msec}$ may be more stable and genetically determined.

These reasons suggest that focusing on early components and a stimulus parameter such as intensity, which is known to affect early components, would produce data more readily interpretable than had previously been possible.

The amplitude-intensity function was chosen for study because wide and relatively stable individual

*The author wishes to thank Lyman C. Wynne and Adolf Pfefferbaum for their help in planning this project, and Carolyn Gruner, Catherine King, and Arlene Ammerman for technical assistance. differences have been found in the rate at which AER amplitude changes with increasing stimulus intensity (Buchsbaum \& Pfefferbaum, 1971; Buchsbaum, 1971; Buchsbaum \& Silverman, 1968; Soskis \& Shagass, 1974). Two patterns of response have been noted: augmenting, the tendency for AER amplitude to increase with increasing stimulus intensity; and reducing, the tendency for amplitude to decrease with increasing stimulus intensity. It has been hypothesized that these two different patterns of response might reflect a central nervous system mechanism for modulating the levels of sensory input. Several techniques have been used to measure individual differences in stimulus intensity response. These have included brief flashes (Buchsbaum \& Pfefferbaum, 1971), 500-msec light square waves (Buchsbaum et al, 1973), and sinusoidally modulated light (Spilker \& Callaway, 1969; Soskis \& Shagass, 1974). Both square waves and sine waves were used in this study to compare the two techniques. AER variability of the AER from trial to trial was a heritable characteristic that might obscure any genetic effects on AER amplitude.

\section{METHOD}

Sixty-seven normal adult twin pairs (33 monozygotic and 34 dizygotic) were recruited from local twin clubs, acquaintances of other twin Ss, and viewers of a television program about twin research. They ranged in age from 18 to 57, and both groups had equal numbers of men and women; all pairs of $\mathrm{DZ}$ twins were of the same sex. Zygosity was confirmed by a 15-group blood typing.

\section{AER Technique}

EEG Recording Technique. For the visual stimulus intensity and variability procedures, EEG was recorded between vertex and right ear. For the sine-wave procedure, two channels of EEG, left occiput-left ear and right occiput-right ear, were recorded.

EEG was recorded, amplified $(3 \mathrm{~dB}$, bandwith 0.3 , and $116 \mathrm{~Hz}$ ), filtered (high-frequency cutoff, $40 \mathrm{~Hz}$; down $60 \mathrm{~dB}$ at $42 \mathrm{~Hz}$ ) and digitized on line at $250 \mathrm{~Hz}$ by the LINC computer. All stimulus presentation was controlled on line (Gips et al, 1971). 
TWIN PAIR I

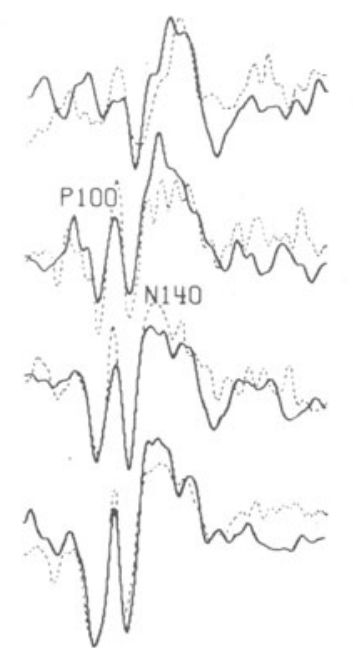

Fig. 1. Visual average evoked responses (AERs) in two pairs of MZ twins. Illustrated are AERs to four intensities of light from top to bottom, dim to bright. For each pair, the AER is shown as a solid line for one twin and as a dotted line for the cotwin. Note similarity in latency of peaks, waveform, and changes with stimulus intensity. For Pair 1, the component P100-N140 increases markedly with intensity; for Pair 2 this same component decreases with increasing stimulus intensity.

(1) Visual stimulus intensity: Stimuli were 1-sec pulses of light at four different intensities presented in a pseudorandom order with 64 presentations of each intensity in an 8-min experimental run. The AERs were computed separately for each intensity for a 500-msec epoch for both "on" and "off" responses. The stimuli were generated by an Iconix photostimulator and two fluorescent tubes, and were presented to the $S$ from behind a 40 x $25 \mathrm{~cm}$ diffuse plastic screen $50 \mathrm{~cm}$ in front of the S's eyes.

(2) Auditory AER variability: Auditory stimuli were generated by the LINC computer D/A, and after amplification (Bogen CHB 10A amplifier, 20-W peak power output) presented through a speaker placed $1 \mathrm{~m}$ directly in front of the $\mathrm{S}$. The stimuli were $60-\mathrm{dB} 500-\mathrm{Hz}$ tones of $500 \mathrm{msec}$ duration separated by an interval of $500 \mathrm{msec}$. A total of 512 tones were presented, and eight separate AER computed, each based on 64 independent, randomly selected stimuli from the 512 tones.

(3) Sinusoidally modulated light: The stimuli consisted of a $10-\mathrm{Hz}$ sine-wave modulated light driven to four depths of modulation $(11 \%, 24 \%, 34 \%$, and $42 \%)$ about a mean intensity of $100 \mathrm{fL}$, each of which was presented for $36 \mathrm{sec}$ or 360 cycles. The stimuli were presented in ascending order of depth of modulation, and at the end of each presentation there was a 20 -sec pause during which the $S$ watched the light of mean intensity without modulation.

\section{Experimental Protocol}

Each $S$ received each AER procedure in the same order on two separate occasions, generally 2 weeks apart. These AER tests were part of a larger group of other psychophysiologic and personality tests to be reported elsewhere. In all cases, data are based on the mean results for the two sessions.

\section{Data Analysis}

Four-Intensity Visual AER. The AERs were measured in three ways, and heritability estimates were made using each.

(1) Visual examination: AER amplitude was measured from peak to trough, from a positive peak $(P)$ at approximately 80 to $100 \mathrm{msec}(\mathrm{P} 100)$ to a negative peak $(\mathrm{N})$ at approximately
$140 \mathrm{msec}$ (N140) and from the negative peak to a positive one at approximately $200 \mathrm{msec}$ (P200). Using data from both sessions, we attempted to select components which clearly appeared in all four intensities for both days. Amplitude was also measured relative to a prestimulus baseline, for each of the three components.

(2) Mean deviation: We calculated the mean absolute deviation from zero baseline over three time bands centered on the three peaks $(76-112,116-152$, and $168-248 \mathrm{msec})$. These time bands were based on visual identification of the three major peaks, P100(P1), N140(N1), and P200(P2), usually identified in vertex evoked potentials. They correspond fairly well with time bands used by Lewis et al (1972). The mean value of each evoked response was used as a baseline. This baseline was subtracted from each AER coordinate. Within each time band, the mean of the absolute values of successive coordinates was calculated. This yielded the mean deviation from baseline in microvolts.

(3) Line length: In order to provide comparison with the data from Lewis et al (1972), a map measure or line length computation was done, calculating the mean of the absolute values of point-to-point differences for each of the three time bands.

(4) Individual AER values: Each 4-msec time coordinate of the AER after removal of the mean value of the entire AER curve was used as an amplitude value.

Sine-Wave Stimulation. The amplitude of activity for $10-\mathrm{Hz}$ (first harmonic) and $20-\mathrm{Hz}$ (second harmonic) was determined by Fourier analysis for each intensity, for each lead.

Auditory Variability. Both AER variances and product moment correlations on split-half replicates were computed. For the variance computation, first the mean level for each curve was subtracted from each coordinate. The standard deviation of the eight values for each coordinate was then calculated. These point-by-point standard deviations were then averaged for seven overlapping time bands; 0-128, 64-192, 128-256, 192-320, 256-384, 320-448, and 384-500 msec. For the product moment correlations, two separate AERs were computed, each based on 256 of the 512 tones. As for the variance computation, product moment correlations were calculated between replicate halves for each of the seven time bands; see Callaway and Halliday (1973) for a discussion of these techniques.

Amplitude-Intensity Slope Computation. A measure of the rate of increase of the AER amplitude with increasing stimulus intensity was achieved by fitting a straight line to the amplitude measurements, the mean deviations, the 4-msec time coordinates, and the Fourier amplitudes that were obtained for each of the four intensities or four depths of modulation, using the least squares techniques. Thus, the slope of the line indicated the relative rate of increase of AER amplitude with increasing light intensity.

Heritability. In every table, the intraclass correlations between $\mathrm{MZ}$ and DZ twins are shown. A measure of heritability (see discussion by Jensen, 1967) was calculated:

$$
\mathrm{H}=(\mathrm{rMZ}-\mathrm{rDZ}) /(1 .-\mathrm{rDZ})
$$

\section{RESULTS}

\section{Four-Intensity Visual AER}

As expected, MZ twins resembled each other more than did DZ twins. Typical MZ twin pair AERs are shown in Fig. 1. Not only are waveforms quite similar within a pair, but change in amplitude with intensity is also very similar. Fig. 2 illustrates AERs for the $80-\mathrm{fL}$ stimulus for each MZ pair; remarkable similarity in waveform, latency, and amplitude within MZ pairs is apparent. Intraclass correlations for the visual identification (peak to trough) and mean deviation AER 
measures are shown in Table 1 . Note that the MZ-DZ differences tend to be greater for slope measures than for amplitude measures. It is also of interest that, for the slope measure, the DZ correlations fall nearly to zero in many instances. Separate examination of the intraclass correlations for the amplitude of the AER for each stimulus intensity further indicates the importance of stimulus intensity. Using the mean deviation measure for 76-112 msec to assess amplitude, we found the following correlations for $\mathrm{MZ}$ twins for the four stimulus intensities from dim to bright: $-.20,+.31,+.40$, and +.51 . For DZ twins, the correlations were: $-.21,+.07$, +.02 , and -.04 .

Figure 3 illustrates the point-by-point analysis with both amplitude and slope measures for comparison. The point-by-point slope demonstrates that amplitude for the total group decreased with intensity at about $100 \mathrm{msec}$, did not change at about $140 \mathrm{msec}$, and increased strikingly at about $200 \mathrm{msec}$. Indeed, the maximum and minimum very closely correspond to the mean latency for visual examination of P100 and P200, as indicated by the circled points. Note that the value at $100 \mathrm{msec}$ is actually negative, indicating that AER values were lower for high intensities than for low ones at this point. The intraclass correlations for $\mathrm{MZ}$ twins for individual points at the peaks and either side are shown in Table 1. The two positive peaks had higher MZ correlations and higher MZ-DZ differences than the negative peak.

Next, we calculated the "heritability" for each point of the curve. Heritability peaks for the slope measure strikingly coincide with the hand-identified latencies. In contrast, the amplitude curve shows less heritability for much of the curve and no such clear peak alignment.

Peak latencies were also very similar in MZ twins (Table 2). As for the point-by-point and baseline-to-peak measures, the N140 latency tends to show lower heritability than the two positive peaks.

Sine-Wave AER. For both amplitude and slope, high MZ intraclass correlations and relatively high heritabilities were observed. As in the visual stimulus intensity experiment, slope measures generally yielded higher $\mathrm{MZ}$ correlations and lower $\mathrm{DZ}$ correlations than did amplitude measures. The highest heritability was observed for the slope measure, second harmonic.

The extent of hemispheric asymmetry also appears to be heritable for the second-harmonic measure, as can be seen for the absolute value of left-right differences. This was calculated separately for each depth of modulation and then averaged across intensities. However, if one MZ twin had larger amplitudes in the left occipital EEG, then his twin was likely to have larger amplitude on the right; the intraclass correlation for mean raw left-right differences in MZ twins was $-0.47(p<.05)$, and for absolute left-right differences was $+0.67(\mathrm{p}<.01)$. This striking mirror imaging was far less apparent in $\mathrm{DZ}$ twin pairs.
AER Variability. Variability measures exhibited MZ intraclass correlations in the same range as amplitude or latency measures, but showed higher DZ correlations as well. Thus, lower heritabilities are seen in Table 3. Both variance and correlation techniques show higher heritability after $300 \mathrm{msec}$. For all bands except $192-320 \mathrm{msec}$, the correlation technique yields higher $\mathrm{MZ}$ intraclass correlations than the standard deviation technique.

\section{DISCUSSION}

All types of amplitude quantification indicated that AERs show significant familial effects; MZ intraclass correlations were generally in the range of 0.40 to 0.60 $(p<.05$ for $r>.38$, with our sample size) for both amplitudes and amplitude-intensity slopes. Amplitude-intensity slopes tended to have higher $\mathrm{MZ}$ correlations than mean amplitude measures, especially
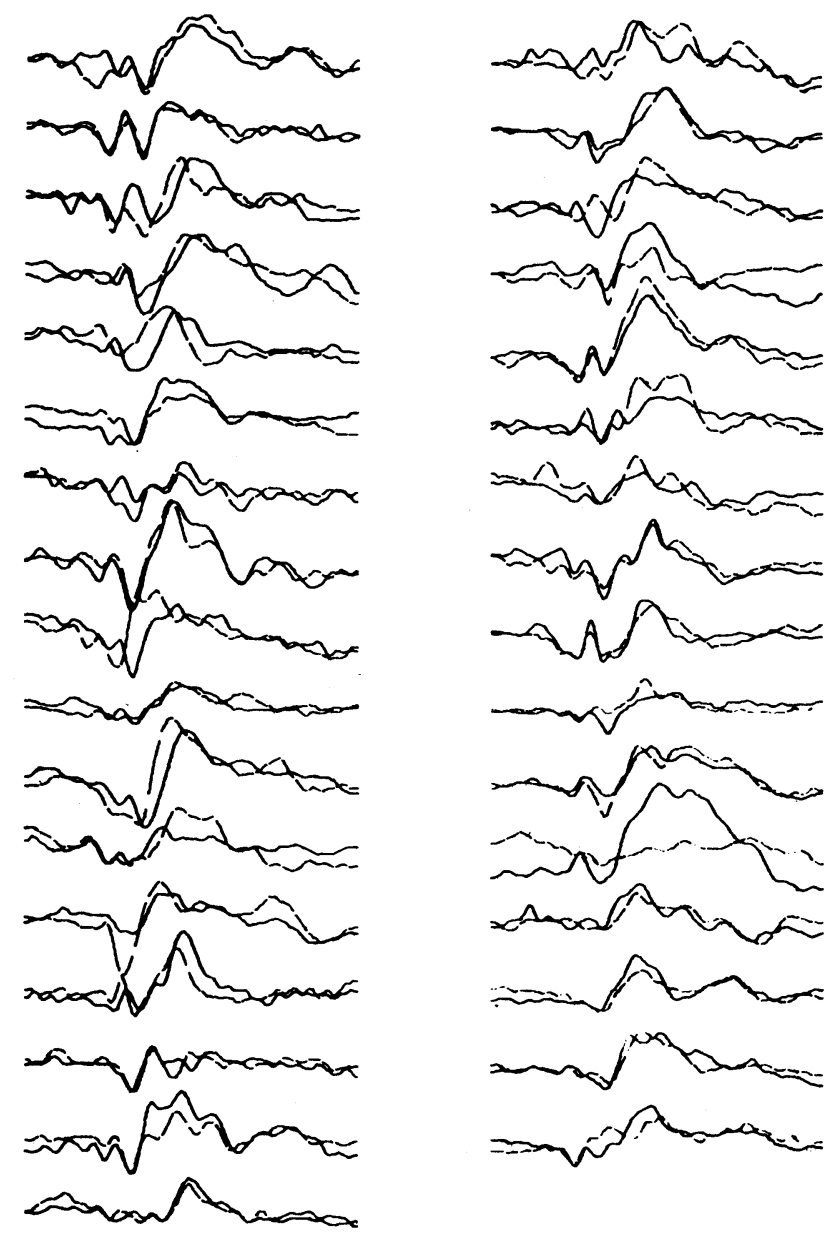

Fig. 2. Visual AER for the 80-fL stimulus for each MZ pair, with one twin shown as a solid line and one as a dotted line. The range of variation in waveform and amplitude across individuals is wide, but remarkable similarity is shown within twin pairs. 
Table 1

\begin{tabular}{|c|c|c|c|c|c|c|}
\hline & \multicolumn{3}{|c|}{$\begin{array}{c}\text { Mean } \\
\text { Amplitude }\end{array}$} & \multicolumn{3}{|c|}{$\begin{array}{c}\text { Amplitude- } \\
\text { Intensity Slope }\end{array}$} \\
\hline & $\mathrm{rMZ}$ & $\mathrm{rDZ}$ & $\mathbf{h}$ & $\mathrm{rMZ}$ & $\mathrm{rDZ}$ & $\mathrm{h}$ \\
\hline $\begin{array}{l}\text { Visual Inspection } \\
\text { P100-N140 } \\
\text { N140-P200 }\end{array}$ & $\begin{array}{l}.59 \\
.57\end{array}$ & $\begin{array}{l}.36 \\
.10\end{array}$ & $\begin{array}{l}.35 \\
.52 *\end{array}$ & $\begin{array}{l}.51 \\
.56\end{array}$ & $\begin{array}{l}-.04 \\
-.10\end{array}$ & $\begin{array}{l}.52 * \\
.60^{*}\end{array}$ \\
\hline $\begin{array}{l}\text { Mean Deviation } \\
76-112 \\
116-152 \\
168-248\end{array}$ & $\begin{array}{r}\text { (Msec) } \\
.39 \\
.57 \\
.38\end{array}$ & $\begin{array}{r}-.04 \\
.17 \\
-.03\end{array}$ & $\begin{array}{l}.41^{*} \\
.46^{*} \\
.39^{*}\end{array}$ & $\begin{array}{l}.51 \\
.60 \\
.51\end{array}$ & $\begin{array}{l}.00 \\
.28 \\
.06\end{array}$ & $\begin{array}{l}.51^{*} \\
.44^{*} \\
.47^{*}\end{array}$ \\
\hline $\begin{array}{l}\text { Point-by-Point } \\
68 \\
84 \\
100(\mathrm{P} 100) \\
116 \\
140(\mathrm{~N} 140) \\
172 \\
204(\mathrm{P} 200) \\
228\end{array}$ & $\begin{array}{l}.19 \\
.34 \\
.51 \\
.54 \\
.43 \\
.49 \\
.43 \\
.59\end{array}$ & $\begin{array}{l}.44 \\
.17 \\
.10 \\
.48 \\
.57 \\
.20 \\
.14 \\
.21\end{array}$ & $\begin{array}{c}-.44 \\
.20 \\
.45^{*} \\
.11 \\
-.32 \\
.36 \\
.33 \\
.48^{*}\end{array}$ & $\begin{array}{l}.22 \\
.56 \\
.71 \\
.59 \\
.69 \\
.30 \\
.72 \\
.76\end{array}$ & $\begin{array}{l}.02 \\
.04 \\
.09 \\
.39 \\
.27 \\
.05 \\
.36 \\
.14\end{array}$ & $\begin{array}{l}.20 \\
.54^{*} \\
.68^{*} \\
.32 \\
.57^{*} \\
.26 \\
.56^{*} \\
.72^{*}\end{array}$ \\
\hline
\end{tabular}

*Indicates MZ-DZ correlation difference, $p<.05$, one-tailed.

for the mean deviation and point-by-point techniques. Examination of many AERs suggests that the most common reducer pattern is an increase in amplitude up to the 80-100-fL level and then a decrease in amplitude for the fourth intensity. Thus, we expected individual differences to be greatest for the fourth intensity. The heritabilities calculated for each intensity (using mean deviation data for $76-112 \mathrm{msec}$ ) from dim to bright, $0.00,0.25,0.39$, and 0.54 , are consistent with this impression.

Heritability estimates were also higher for slope measures because of the low DZ correlations observed.
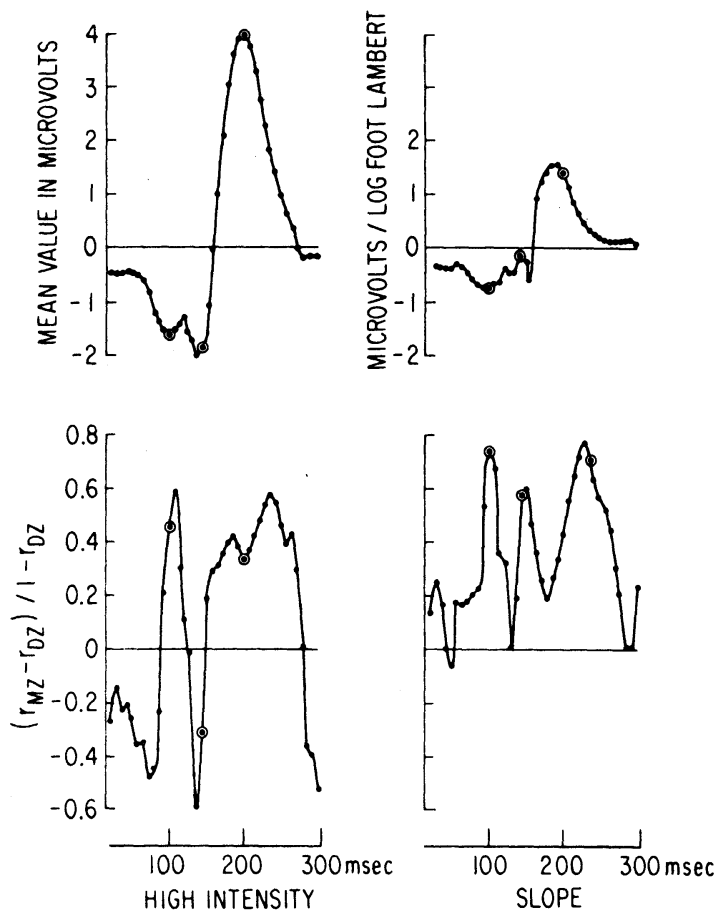

Fig. 3. Analysis of AER amplitude, slope, and "heritability" for consecutive 4-msec intervals. Above, mean AER amplitude for $120 \mathrm{Ss}$ (left) and mean slope for each time coordinate. Below, "heritability" obtained for each time coordinate. Circled points are the mean latencies (across intensities) for P100, N140, and P200 for the entire group of twins as determined by visual inspection of AER components. Note that the circled points fall: (1) on the minima and maxima of the mean slope curve, and (2) on the maxima of the "heritability" curve for slope, not amplitude.

Table 2

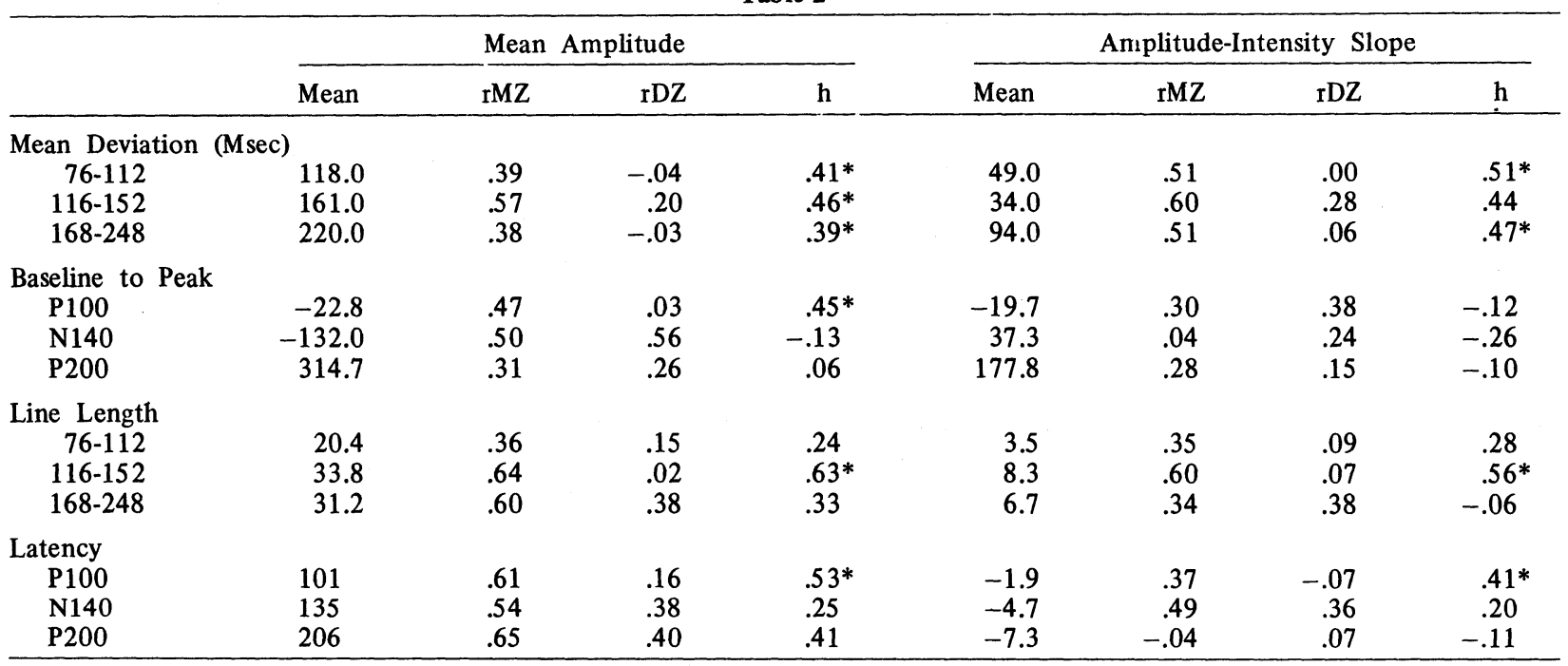

*Indicates MZ-DZ correlation difference, $p<.05$, one-tailed. 
These low DZ correlations might occur if identicality of several genes were necessary for the expression of the augmenter or reducer phenotype. Although it could be argued that this might result from disassortative mating, our data on a small sample of families $(\mathrm{N}=9)$ indicate that, for Peak P100-N140, the correlation between fathers and mothers was $0.61(\mathrm{p}<.05)$ for amplitudeintensity slopes.

The finding that females of all ages and XO patients showed larger amplitudes and greater increases in amplitude with increasing stimulus intensity than did males (Buchsbaum et al, 1974b) suggests that the sex chromosomes may be important in AER inheritance. Since children aged 6-10 and adults over 40 showed similar sex differences, hormonal factors cannot furnish the entire explanation of the sex differences in AER size.

The observed slope differences seem unlikely to have resulted from pupillary or retinal factors. Since intensities were randomized, amplitude-intensity slope differences could not arise from differences relating to pupillary response or retinal recovery from the preceding stimulus. Further, studies of the effect of pupillary size on the visual vertex AER in our laboratory (using both pilocarpine and neosynepherine) and elsewhere (Kooi \& Bagchi, 1964; Soskis \& Shagass, 1974) have not demonstrated a significant influence, although occipital EEG leads may show larger AERs with pupillary dilatation (Richey et al, 1966). Studies of a patient with abetalipoproteinemia, which causes retinal dysfunction, also failed to show vertex AER changes either on baseline or on treatment with Vitamin A. Finally, such other peripheral factors as head shape (Dustman \& Beck, 1965) and skull or scalp thickness (Buchsbaum et al, 1974b) have not been found to affect the AER systematically.

The finding of mirror-image asymmetry in sine-wave AER is consistent with the data of Raney (1939), who found that 12 of $17 \mathrm{MZ}$ twin pairs showed occipital alpha EEG amplitude greater on the right side in one twin and on the left side in the other. No beta frequency analysis was done, however. Despite this mirror-imaging,
Table 3

\begin{tabular}{cccccccc}
\hline & \multicolumn{3}{c}{ Standard Deviation } & & \multicolumn{3}{c}{ Correlation } \\
Time & rMZ & rDZ & h & & rMZ & rDZ & h \\
\hline $0-128$ & .21 & .33 & -.17 & & .35 & .36 & -.01 \\
$64-192$ & .38 & .39 & -.01 & & .40 & .40 & .00 \\
$128-256$ & .37 & .37 & .00 & & .39 & .52 & -.27 \\
$192-320$ & .58 & .41 & .28 & & .50 & .44 & .10 \\
$256-384$ & .30 & .29 & .01 & & .50 & .35 & .23 \\
$320-448$ & .27 & .05 & .23 & & .48 & .11 & .41 \\
$384-500$ & .22 & .05 & .17 & & .52 & .29 & .32 \\
$0-500$ & & & & & .54 & .44 & .17 \\
\hline
\end{tabular}

the absolute amount of asymmetry appears to be heritable. This finding is of interest, especially in view of links between the amount of AER asymmetry and intelligence in children (Rhodes et al, 1969).

While MZ intraclass correlations for variability measures ranged from 0.35 to 0.52 for the correlation coefficient method, DZ correlations were high enough so that MZ-DZ differences were not significant. This may reflect the relatively low reliability of the measure; we obtained test-retest correlations between the first and second sessions of .40 to .49 . These are somewhat higher than those reported by Callaway and Halliday (1973). Species differences in AER stability were noted by Creel et al (1973), and reliable individual differences in intraindividual variability in task performance are well known (see Carron \& Bailey, 1969). Improved techniques for estimating trial-to-trial variability will further evaluate the heritability of AER variability. Nevertheless, common genetics and rearing do produce similar levels of AER variability as assessed by these techniques.

When point-by-point or baseline-to-peak analysis is used, our data tend to indicate higher heritability of the two positive AER components than of the negative one; latency heritability is also low for N140. This finding may partly reflect the low variance in the population for the latency of $\mathrm{N} 140(\mathrm{SD}=13 \mathrm{msec})$ in comparison to $\mathrm{P} 100(\mathrm{SD}=19 \mathrm{msec})$ or $\mathrm{P} 200(\mathrm{SD}=21 \mathrm{msec})$. Amplitude variance was also smaller for the negative $116-152-\mathrm{msec}$ time band (coefficient of variation $=39 \%$ )

Table 4

\begin{tabular}{|c|c|c|c|c|c|c|}
\hline & \multicolumn{3}{|c|}{ Mean Amplitude } & \multicolumn{3}{|c|}{ Amplitude-Intensity Slope } \\
\hline & $\mathrm{rMZ}$ & $\mathrm{rDZ}$ & $\mathrm{h}$ & $\mathrm{rMZ}$ & $\mathrm{rDZ}$ & $\mathbf{h}$ \\
\hline $\begin{array}{l}\text { L Occiput } 1 \text { st Harmonic } \\
\text { R Occiput } 1 \text { st Harmonic }\end{array}$ & $\begin{array}{l}.65 \\
.63\end{array}$ & $\begin{array}{l}.23 \\
.45\end{array}$ & $\begin{array}{l}.54^{*} \\
.32\end{array}$ & $\begin{array}{l}.46 \\
.34\end{array}$ & $\begin{array}{r}-.09 \\
.22\end{array}$ & $\begin{array}{l}.50^{*} \\
.45^{*}\end{array}$ \\
\hline $\begin{array}{l}\text { L Occiput 2nd Harmonic } \\
\text { R Occiput } 2 \text { nd Harmonic }\end{array}$ & $\begin{array}{l}.56 \\
.63\end{array}$ & $\begin{array}{l}.37 \\
.44\end{array}$ & $\begin{array}{l}.30 \\
.33\end{array}$ & $\begin{array}{l}.46 \\
.68\end{array}$ & $\begin{array}{l}.30 \\
.08\end{array}$ & $\begin{array}{l}.22 \\
.66^{*}\end{array}$ \\
\hline $\begin{array}{l}L-R \text { 1st Harmonic } \\
L-R \text { 2nd Harmonic }\end{array}$ & $\begin{array}{l}-.12 \\
-.47\end{array}$ & $\begin{array}{l}.39 \\
.21\end{array}$ & $\begin{array}{l}-.83 \\
-.86\end{array}$ & $\begin{array}{r}.25 \\
-.18\end{array}$ & $\begin{array}{r}.17 \\
-.06\end{array}$ & $\begin{array}{r}.09 \\
-.11\end{array}$ \\
\hline $\begin{array}{l}\mathrm{L}+\mathrm{R} \text { 1st Harmonic } \\
\mathrm{L}+\mathrm{R} \text { 2nd Harmonic }\end{array}$ & $\begin{array}{l}.69 \\
.70\end{array}$ & $\begin{array}{l}.35 \\
.44\end{array}$ & $\begin{array}{l}.52 * \\
.46 *\end{array}$ & $\begin{array}{l}.43 \\
.60\end{array}$ & $\begin{array}{r}-.19 \\
.21\end{array}$ & $\begin{array}{l}.52 * \\
.49 *\end{array}$ \\
\hline $\begin{array}{l}|\mathrm{L}-\mathrm{R}| \text { 1st Harmonic } \\
|\mathrm{L}-\mathrm{R}| \text { 2nd Harmonic }\end{array}$ & $\begin{array}{l}.34 \\
.67\end{array}$ & $\begin{array}{l}.19 \\
.22\end{array}$ & $\begin{array}{l}.18 \\
.57^{*}\end{array}$ & & & \\
\hline
\end{tabular}

*Indicates MZ-DZ correlation difference, $p<.05$, one-tailed. 
than for the positive 76-112-msec time band ( $\mathrm{CV}=$ $53 \%)$. For line length, however, the negative time band shows the higher heritabilities, perhaps reflecting that measure's sensitivity to minor waveform variations as well as to amplitude. Another explanation of the low heritability of the N140 component may be our failure to control for attentional effects which may be most consistently reflected in this component. Using baseline-to-peak measures, Shevrin and Rennick (1967) suggested that negativity of the N140 component might be specifically related to attention. Most of the investigators studying AER and attention, who measured more than one peak and used a baseline reference so that negativity could be specifically evaluated, have also found their largest attentional effects in this component (e.g., Haider et al, 1964; Harter \& Salmon, 1972; Naatanen, 1967; Wilkinson \& Morlock, 1967).

Individual differences in AER amplitude-intensity response have been linked to individual differences in behavior in cats (Hall et al, 1970) and humans (Buchsbaum \& Silverman, 1968; Buchsbaum \& Pfefferbaum, 1971). Similar amplitude-intensity functions are found for both auditory and visual AER (Schecter \& Buchsbaum, 1973). Based on these studies, we have suggested a model of a central nervous system mechanism which modulates the intensity of incoming stimulation. The tendency to reduce sensation might be useful in coping with sensory overload or pain; the adaptive advantage of such a protective mechanism would very likely be linked to environmental stimulus levels. But, despite the potential advantages of "reducing" in our noisy modern world, this tendency, if excessively or inappropriately applied, might be an underlying factor or symptom of psychopathology-i.e., schizophrenic withdrawal or depression. Indeed, recent AER studies of unmedicated, acute schizophrenics and unipolar depressed patients have shown a preponderance of reducers in these groups. Given the fairly well-established genetic contribution to the predisposition to develop these psychiatric disorders (Rosenthal, 1971; Baker et al, 1972), the finding of genetic determination of the amplitude-intensity function suggests that it may be a valuable technique for exploring the link between genetic determination and phenotypic expression.

\section{REFERENCES}

Baker, M., Dorzab, J., Winokur, G., \& Cadoret R. Depressive disease: Evidence favoring polygenic inheritance based on an analysis of ancestral cases. Archives of General Psychiatry, 1972, 27, 320-327.

Buchsbaum, M. Neural events and psychophysical law. Science, 1971, 170, 998 .

Buchsbaum, M., Coppola, R., \& Bittker, T. E. Differential effects of "congruence," stimulus meaning and information on early and late components of the average evoked response. Neuropsychologia, 1974a, in press.

Buchsbaum, M., Henkin, R. E., \& Christiansen, R. L. Age and sex differences in averaged evoked responses in a normal population with observations on patients with gonadal dygenesis. Electroencephalography \& Clinical Neurophysiology, $1974 \mathrm{~b}$, in press.

Buchsbaum, M., Landau, S., Murphy, D., \& Goodwin, F. Average evoked response in bipolar and unipolar affective disorders:
Relationship to sex, age of onset, and monoamine oxidase. Biological Psychiatry, 1973, 7, 199-212.

Buchsbaum, M., \& Pfefferbaum, A. Individual differences in stimulus intensity response. Psychophysiology, 1971, 8, 600-611.

Buchsbaum, M., \& Silverman, J. Stimulus intensity control and the cortical evoked response. Psychosomatic Medicine, 1968, 30, 12-22.

Callaway, E., \& Halliday, R. A. Evoked potential variability: Effects of age, amplitude and methods of measurement Electroencephalography \& Neurophysiology, 1973, 34, 125-134.

Carron, A. V., \& Bailey, D. A. Evidence for reliable individual variability. Perceptual \& Motor Skills, 1969, 28, 843-846.

Creel, D. J., Dustman, R. E. \& Beck, E. C. Visually evoked responses in the rat, guinea pig, cat, monkey and man Experimental Neurology, 1973, 40, 351-366.

Dustman, R. E., \& Beck, E. C. The visually evoked potential in twins. Electroencephalography \& Clinical Neurophysiology, $1965,19,570-575$

Eason, R. G., Harter, M. R., \& White, C. T. Effects of attention and arousal on visually evoked cortical potentials and reaction time in man. Physiology \& Behavior, 1969, 4, 284-289.

Gips, J., Pfefferbaum, A., \& Buchsbaum, M. Use of a small process control computer in a psy chophysiological laboratory. Psychophysiology, 1971, 8, 538-542.

Haider, M., Spong, P., \& Lindsley, D. B. Attention, vigilance, and cortical evoked-potentials in humans. Science, 1964, 145, 180-182.

Hall, R. A., Rappaport, M., Hopkins, H. K., \& Silverman, J. Evoked response and behavior in cats. Science, 1970, 170, 998-1000.

Harter, M. R., \& Salmon, L. E. Intra-modality selective attention and evoked cortical potentials to randomly presented patterns. Electroencephalography \& Clinical Neurophysiology $1972,32,605-613$.

Hilly ard, S. A., Hink, R. F., Schwent, V. L., \& Picton, T. W. Electrical signs of selective attention in the human brain. Science, 1973, 182, 177-180.

Jensen, A. R. Estimation of the limits of heritability of traits by comparison of monozygotic and dizygotic twins. Proceeding of the National Academy of Science, 1967, 58, 149-156.

Kooi, K. A., \& Bagchi, B. K. Observations on early components of the visual evoked response and occipital rhythms. Electroencephalography \& Clinical Neurophysiology, 1964, $17,638-643$

Lewis, E. G., Dustman, R. E., \& Beck, E. C. Evoked response similarity in monozygotic, dizygotic and unrelated individuals: A comparative study. Electroencephalography \& Clinical Neurophysiology, 1972, 23, 309-316.

Naatanen, R. Selective attention and evoked potentials. Annales Academiae Scientiarum Fennicae, 1967, 151, 1-226.

Osborne, R. T. Heritability estimates for the visual evoked response. Life Sciences, 1970, 9, 481-490.

Raney, E. T. Brain potentials and lateral dominance in identical twins. Journal of Experimental Psychology, 1939, 24, 21-39.

Rhodes, L. E., Dustman, R. E., \& Beck, E. C. The visual evoked response: A comparison of bright and dull children. Electroencephalography \& Clinical Neurophysiology, 1969, 27, 364-372.

Richey, E. T., Kooi, K. A., \& Waggoner, R. W. Visually evoked responses in migraine. Electroencephalography \& Clinical Neurophysiology, 1966, 21, 23-27. Rosenthal, D. A program of research on heredity in
schizophrenia. Behavioral Science, 1971, 16, 191-201.

Roth, W. T. Auditory evoked responses to unpredictable stimuli. Psychophysiology, 1973, 10, 125-138.

Schecter, G., \& Buchsbaum, M. The effect of attention, stimulus intensity and individual differences on the average evoked response. Psychophysiology, 1973, 10, 392-400.

Shevrin, H., \& Rennick, P. Cortical response to a tactile stimulus during attention, mental arithmetic and free associations. Psychophysiology, 1967, 3, 381-388.

Soskis, D. \& Shagass, C. Evoked potential tests of augmenting-reducing. Psychophysiology, 1974, 11, 175-190.

Spilker, B., \& Callaway, E. "Augmenting" and "reducing" in averaged visual evoked responses to sine wave light. Psychophysiology, 1969, 6, 49-57.

Tueting, P., Sutton, S. \& Zubin, J. Quantitative evoked potential correlates of the probability of events. Psychophysiology, 1971, 7, 385-394.

Wilkinson, R. T., \& Morlock, H. C. Auditory evoked response and reaction time. Electroencephalography \& Clinical Neurophysiology, 1967, 23, 50-56.

Young, J. P. R., Lader, M. H., \& Fenton, G. W. A twin study of the genetic influences on the electroencephalogram. Journal of Medical Genetics, 1972, 9, 13-16. accepted May 16, 1974.) 